\title{
Influence of Externally Bonded CFRP on the Shear Behavior of Strengthened and Rehabilitated Reinforced Concrete T-Beams Containing Shear Stirrups
}

\author{
Mu'tasime Abdel-Jaber 1,2,+
}

1 Department of Civil Engineering, The University of Jordan, Amman 11942, Jordan; m.abduljaber@ju.edu.jo or m.abdeljaber@ammanu.edu.jo

2 Department of Civil Engineering, Al-Ahliyya Amman University, Amman 19328, Jordan

+ On sabbatical leave from Department of Civil Engineering, The University of Jordan, Amman 11942, Jordan.

Citation: Abdel-Jaber, M. Influence of Externally Bonded CFRP on the Shear Behavior of Strengthened and Rehabilitated Reinforced Concrete T-Beams Containing Shear Stirrups. Fibers 2021, 9, 87. https:/ /doi.org/ $10.3390 /$ fib9120087

Academic Editors: Faiz Shaikh and Constantin Chalioris

Received: 3 October 2021

Accepted: 9 December 2021

Published: 18 December 2021

Publisher's Note: MDPI stays neutral with regard to jurisdictional claims in published maps and institutional affiliations.

Copyright: (C) 2021 by the author. Licensee MDPI, Basel, Switzerland. This article is an open access article distributed under the terms and conditions of the Creative Commons Attribution (CC BY) license (https:/ / creativecommons.org/licenses/by/ $4.0 /)$.
Abstract: This study aims to investigate the effect of using externally bonded carbon fiber reinforced polymer (CFRP) on the strengthening and rehabilitation of reinforced concrete (RC) T-beams reinforced with steel stirrups. Three configurations of CFRP were used: $45^{\circ}$ inclined strips, horizontal straight strips, and U-wrapped sheets. A total of 19 specimens of strengthened and preloaded RC T-beams were experimentally tested. The experimental results were compared with the theoretical values determined according to the ACI $440.2 \mathrm{R}-17$ code. The results proved that all beams containing CFRP recorded higher strength than the control sample, regardless of whether the beams were tested for strengthening or rehabilitation purposes. The horizontal straight strips of the CFRP schemes recorded the highest enhancement in the shear capacity, followed by the U-wrapped sheets and inclined strips. Moreover, the ACI 440.2R-17 code overestimated the capacities of some samples.

Keywords: T-Beams; strengthening; rehabilitation; CFRP; shear strength; experimental and theoretical studies

\section{Introduction}

\subsection{Literature Overview}

Reinforced concrete (RC) structures are used extensively due to their ease of construction and materials availability. However, the deterioration of RC structures with time is an important dilemma to be considered in the design and the maintenance stages during its service life. Concrete slabs and beams are usually cast simultaneously, providing small edges at the top of beams that work with the beam compression zone. This type of beam is called a T-beam due to its shape. The key factor is to determine whether a T-beam behaves as a rectangular or T-section in the location of the neutral axis (NA). If the NA is in the flange, the beam will behave as a rectangular section, while if the NA is in the web, the beam will behave as a T-beam.

During the service life of RC beams, the beams may encounter additional loads that were not considered in the design stage; thus, these beams might fail if their capacities are not sufficient. As a result, the need to find efficient ways to strengthen existing RC beams has become essential. Carbon fiber reinforced polymer (CFRP) composites proved their efficiency in strengthening concrete elements [1]. Previous studies focused on the flexural strengthening [2,3] and shear strengthening of RC rectangle sections [4-22], T-beams [23-32], and prestressed beams [33] using externally bonded CFRP. The results indicated that using CFRP in different schemes improved the shear strength, as the capacity increased with the increase of the number of CFRP layers. Khalifa and Nanni [24] investigated the effect of using CFRP composites on the shear capacity of RC T-beams. Wrapping configurations, CFRP amount, orientation, and end anchorage were considered in the study. The authors concluded that U-wraps recorded a greater contribution to the shear capacity than side 
strips. Mhanna et al. [30] examined the shear behavior of RC rectangle sections and Tbeams strengthened with CFRP wraps. Both the CFRP schemes and the beams' geometry were investigated. The results indicated that the greater the depth of the beam, the better the enhancement in shear capacity. Moreover, beams with a U-wrapping scheme exhibited sudden and brittle failure. However, U-wrapping is a feasible alternative when complete wrapping is hard to implement. In 2020, Benzeguir Z. et al. [31] investigated the size effect of RC T-beams strengthened with externally bonded CFRP L-shaped laminates in shear. Three groups were considered: one control group and two groups strengthened with Lshaped laminates with and without an anchorage system. The anchorage system consisted of embedding the laminates into the flange. The results proved that the anchorage system was efficient in increasing the capacity and ductility of strengthened T-beams. Moreover, the shear capacity decreased with an increase in the size of the beam. In 2020, Chalioris C.E. et al. [34] studied the effect of CFRP U-jacketing on the shear capacity of RC T-beams. The CFRP sheet was placed on three sides of the beam along the entire length. Mechanical anchorage using bolted steel laminates was also considered. The authors stated that the CFRP U-jacketing enhanced the shear capacity of the beams; however, brittle failure occurred due to CFRP debonding. On the other hand, the mechanical anchorage system managed to delay the CFRP debonding.

When RC beams deteriorate, fast and easy rehabilitation methods are needed to reduce the damage. CFRP composites have also proven their efficiency in the rehabilitation process $[35,36]$ because of their characteristics such as lightweight, ease of installation in different types and schemes, and high strength. Jayaprakash et al. [36] studied the effect of using CFRP strips, bonded externally, on the strengthening and rehabilitation of RC T-beams. The results proved that using CFRP composites on pre-cracked T-beams increased their shear capacity when compared with control samples without any CFRP. Moreover, the performance of the pre-cracked beams was better than that of the originally strengthened beams.

\subsection{Paper Objectives and Significance}

This study investigates the shear strengthening and rehabilitating of 19 RC T-beams. The importance of this study is based in the fact that all the beams are designed to behave as T-beams, i.e., NA is designed to be located at the web, and the beams are fully reinforced to study the interaction between the internal shear stirrups and externally bonded CFRP. Three CFRP configurations were used: $45^{\circ}$ inclined strips, horizontal straight strips, and U-wrapped sheets. The specimens of strengthened and preloaded RC T-beams were experimentally tested. The experimental results were compared with the theoretical capacities of all beams that were determined according to the ACI 440.2R-17 code [37].

\section{Materials and Methods}

\subsection{Material Properties}

2.1.1. Concrete and Steel

Ready mix concrete was used for casting all the beams. The cement used was Portland Pozzolana Cement CEM II/A-P, which satisfies the requirements of JS 30-1:2007 and EN 197-1:2005. The cement properties are listed in Table 1 below.

Table 1. Cement technical data.

\begin{tabular}{ccccc}
\hline \multirow{2}{*}{ Requirement } & \multicolumn{2}{c}{ Result (\%) } & \multicolumn{2}{c}{ Standard Values } \\
\cline { 2 - 5 } & Min & Max & Min & Max \\
\hline Fineness (Blaine) $\left(\mathrm{cm}^{2} / \mathrm{g}\right)$ & 4500 & 5000 & & 10 \\
Soundness $(\mathrm{mm})$ & 0.5 & 2 & 60 & \\
Initial setting time $(\mathrm{min})$ & 130 & 165 & 60 \\
\hline
\end{tabular}


The coarse aggregates used were crushed limestone with a nominal maximum aggregate size of $25 \mathrm{~mm}$, while the fine aggregates used were silica sand with a maximum size of $4.76 \mathrm{~mm}$. All the aggregates meet the requirements of JS 96:1987.

Six $(150 \times 150 \times 150 \mathrm{~mm})$ cubes were cast, cured for 28 days, and tested to determine the compressive strength. The average compressive strength was $22.5 \mathrm{MPa}$ at 28 days of curing. Table 2 shows the mix design used in this study.

Table 2. Concrete mix design.

\begin{tabular}{cccc}
\hline Cement $\left(\mathrm{kg} / \mathrm{m}^{\mathbf{3}}\right)$ & Water $\left(\mathrm{kg} / \mathrm{m}^{\mathbf{3}}\right)$ & Coarse Aggregates $\left(\mathrm{kg} / \mathrm{m}^{\mathbf{3}}\right)$ & Fine Aggregates $\left(\mathrm{kg} / \mathrm{m}^{\mathbf{3}}\right)$ \\
\hline 375 & 180 & 1042.97 & 754.178 \\
\hline
\end{tabular}

The steel used for all reinforcement was high yield strength deformed bars and its properties are listed in Table 3.

Table 3. Technical information of steel.

\begin{tabular}{cccc}
\hline $\begin{array}{c}\text { Tested Average Yield } \\
\text { Stress (MPa) }\end{array}$ & $\begin{array}{c}\text { Tested Average Ultimate } \\
\text { Stress (MPa) }\end{array}$ & Elastic Modulus (GPa) & Elongation \\
\hline 550 & 680 & 200 & 14 \\
\hline
\end{tabular}

\subsubsection{CFRP}

Two types of CFRP were used in this study: MasterBrace LAM and MasterBrace FIP. The first type is unidirectional high strength carbon fiber laminates with $2800 \mathrm{MPa}$ tensile strength and $1.4 \mathrm{~mm}$ thickness. The second type is unidirectional carbon sheets with $4900 \mathrm{MPa}$ tensile strength and $0.166 \mathrm{~mm}$ thickness. The properties of both types are shown in Table 4.

Table 4. CFRP technical data.

\begin{tabular}{ccc}
\hline Property & MasterBrace LAM & MasterBrace FIP \\
\hline Modulus of elasticity $(\mathrm{GPa})$ & $>210$ & 230 \\
Tensile strength $(\mathrm{GPa})$ & $>2.8$ & 4.9 \\
Density $\left(\mathrm{g} / \mathrm{cm}^{3}\right)$ & 1.6 & 1.76 \\
Thickness $\left(\mathrm{mm}^{3}\right)$ & 1.4 & 0.166 \\
\hline
\end{tabular}

\subsubsection{Epoxy Resin (Adhesive)}

To ensure adequate bonding between the CFRP and concrete surface, and to avoid any debonding that might occur during the test, a suitable adhesive for each type of the CFRP was used, in which MasterBrace ADH 2200 was used for CFRP laminates and MasterBrace SAT 4500 was used for CFRP sheets. Tables 5 and 6 shows the properties of both resins, respectively.

\subsection{Test Specimens}

\subsubsection{Specimen Details}

A total of nineteen specimens of $2000 \mathrm{~mm}$ length were tested in this study, all having the same cross-section of $500 \mathrm{~mm}$ flange width, $150 \mathrm{~mm}$ web width, an overall depth of $400 \mathrm{~mm}$, and a flange thickness of $50 \mathrm{~mm}$. Figure 1 illustrates the cross-section and reinforcement details of the tested beams.

All specimens were fully designed to fail in shear. The main reinforcement was $2 \Phi 25 \mathrm{~mm}$ and the shear stirrups $(\Phi 10 \mathrm{~mm})$ were used at a minimum spacing of $50 \mathrm{~mm}$ according to the ACI318-19 code [38]. The shear stirrups were included in the specimens to study the effect of the interaction between stirrups and CFRP materials on the experimental shear capacities of the tested beams. Although the stirrups were used at the minimum 
spacing; however, the main reinforcement was also used at the maximum reinforcement ratio. Hence, a failure in shear was expected to happen.

Table 5. MasterBrace ADH 2200 properties.

\begin{tabular}{|c|c|c|}
\hline \multicolumn{2}{|l|}{ Property } & Value \\
\hline \multirow{2}{*}{ Compressive Strength at $25^{\circ} \mathrm{C}$ (BS 6319 part 2) } & day 1 & $40 \mathrm{MPa}$ \\
\hline & day 7 & $65 \mathrm{MPa}$ \\
\hline \multirow{2}{*}{$\begin{array}{c}\text { Flexural strength at } 25^{\circ} \mathrm{C} \text { (ASTM C } 580 \text { part 7) } \\
\text { Tensile Strength at } 25^{\circ} \mathrm{C} \text { (BS } 6319 \text { Part 7) }\end{array}$} & day 7 & $20 \mathrm{MPa}$ \\
\hline & day 7 & $10 \mathrm{MPa}$ \\
\hline \multirow[b]{2}{*}{ Pot life in Minutes } & at $25^{\circ} \mathrm{C}$ & 50 \\
\hline & at $40{ }^{\circ} \mathrm{C}$ & 30 \\
\hline \multirow{2}{*}{ Recoat time in Hours } & at $25^{\circ} \mathrm{C}$ & 8 \\
\hline & at $40^{\circ} \mathrm{C}$ & 6 \\
\hline \multirow{2}{*}{\multicolumn{2}{|c|}{$\begin{array}{c}\text { Bond Strength } \\
\text { Setting time at } 25^{\circ} \mathrm{C}\end{array}$}} & $<2 \mathrm{MPa}$ (concrete failure) \\
\hline & & $12 \mathrm{~h}$ \\
\hline \multicolumn{3}{|c|}{ Meets the requirements of ASTM C 881 Type 1 Grade 3 Class B \& C } \\
\hline
\end{tabular}

Table 6. MasterBrace SAT 4500 properties.

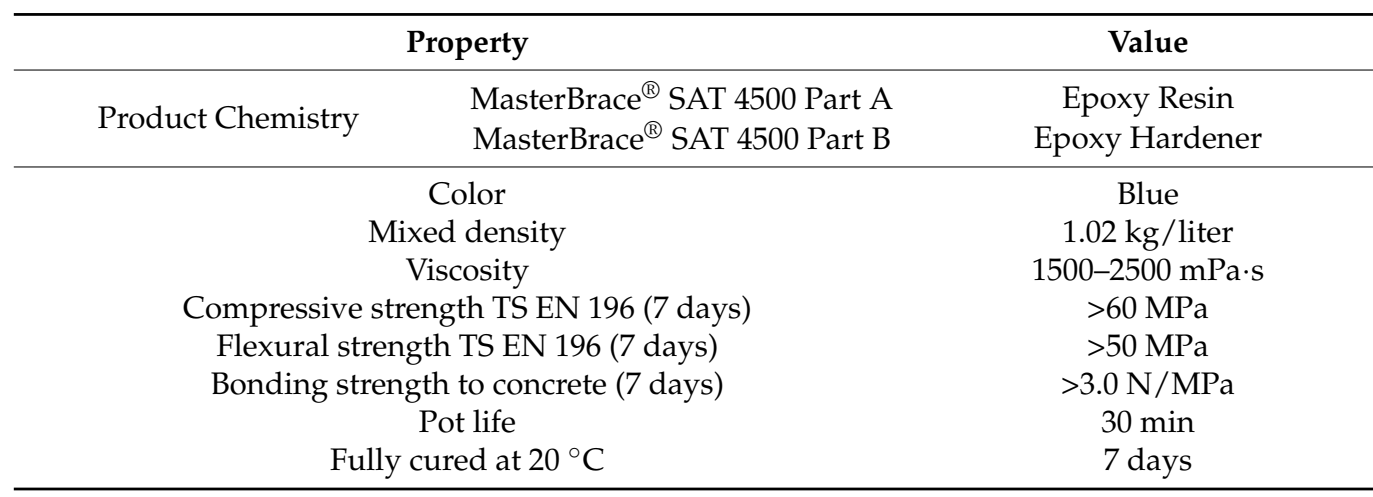

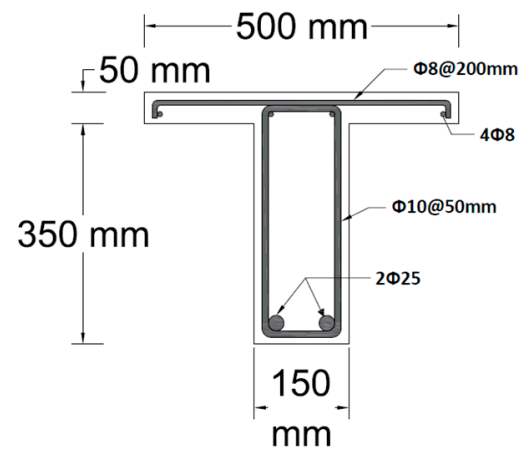

(a)

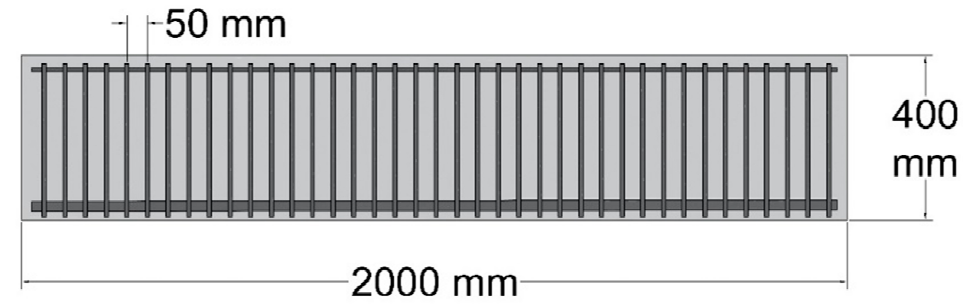

(b)

Figure 1. Section details and reinforcement; (a) cross-section; (b) longitudinal section.

\subsubsection{Test Groups}

The 19 RC T-beams were categorized into four groups as follows:

Group (1): This group consisted of the control sample. No CFRP materials were attached. The purpose of this beam was to compare all the other beams with it. Figure 2a shows the control beam.

Group (2): This group consisted of six beams with $45^{\circ}$ inclined CFRP strips attached to the side faces of each beam. The spacing between any two consecutive CFRP strips 
was $100 \mathrm{~mm}$, the same as the width of each CFRP strip. Three specimens were used for rehabilitation and the other three beams were used for strengthening. Figure $2 b$ shows the CFRP configuration of this group.

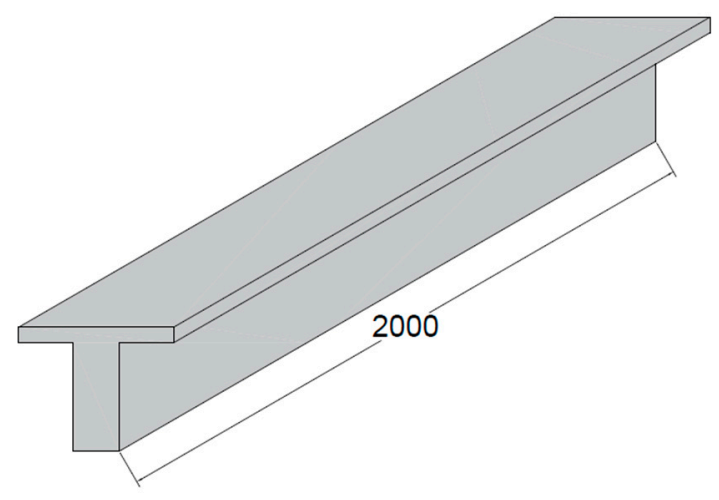

(a)

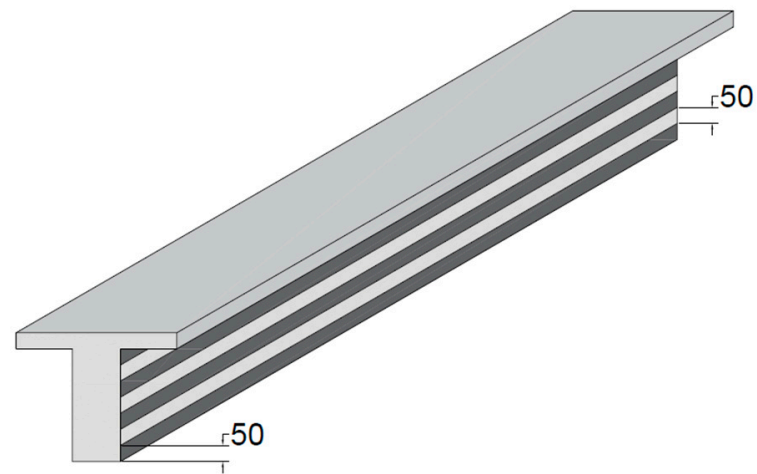

(c)

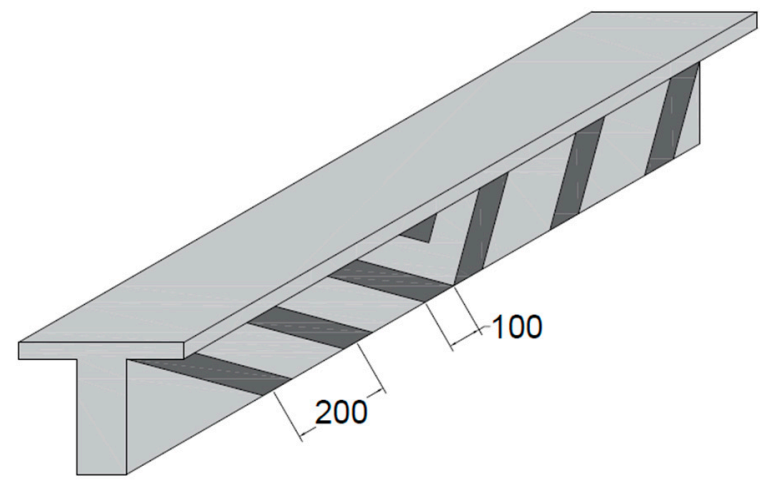

(b)

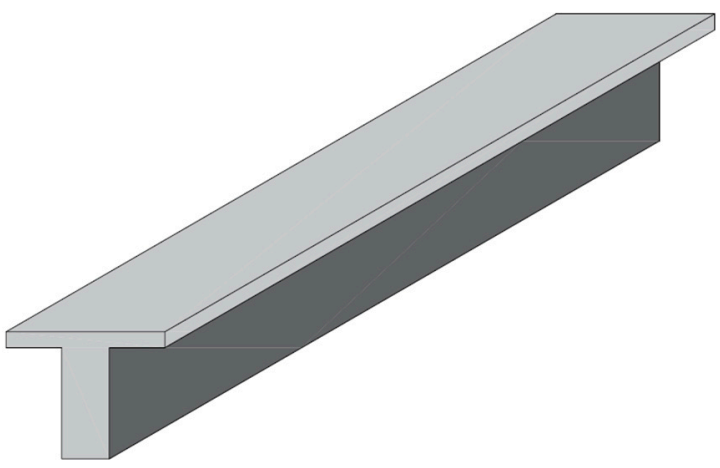

(d)

Figure 2. Beams groups: (a) control group 1; (b) inclined $45^{\circ}$ CFRP-group 2; (c) horizontal straight CFRP-group 3; (d) U-wrap CFRP-group 4.

Group (3): This group consisted of six beams with horizontal straight CFRP strips $\left(0^{\circ}\right.$ inclination) attached to the side faces of each beam over the whole length. The spacing between the CFRP strips was $50 \mathrm{~mm}$. Three specimens were used for rehabilitation and the other three beams were used for strengthening. Figure $2 \mathrm{c}$ shows the CFRP configuration of this group.

Group (4): This group consisted of six beams with U-wrapped CFRP sheets attached to the web face of the beams. Three specimens were used for rehabilitation and the other three beams were used for strengthening. Figure $2 \mathrm{~d}$ shows the CFRP configuration of this group.

The notations of the beams consist of three parts. The first part is strengthening or rehabilitation; $\mathrm{S}$ is designated for strengthening and $\mathrm{R}$ for rehabilitation. The second part is for CFRP configurations; Inc is designated for inclined CFRP strips, Str for horizontal CFRP straight strips, and Sh for CFRP U-wrapped sheets. The third part is the number of the sample tested. For example, the beam R-Str2 is the preloaded beam with horizontal straight CFRP strips and the number of samples is 2 . The control beam is named CB. Table 7 provides a full list of the beams and their notations.

\subsection{Strengthening and Rehabilitation Process}

All beams were cast using a prefabricated steel mold made from $6 \mathrm{~mm}$ steel sheets with stiffeners distributed along the mold length to avoid any local buckling that might occur during concrete pouring; thus, a smooth surface was obtained without the need of any treatment. Figure 3 shows the steel mold and reinforcement cage. An electrical 
vibrator was used to ensure the adequate compaction of the concrete. The epoxy resin was applied to the beam surface and the CFRP was then attached. For the strengthening procedure, the CFRP was attached to the beams before loading, while for the rehabilitation process, the beams were loaded up to $60 \%$ of CB ultimate load and then the CFRP materials were attached.

Table 7. Test specimen notations.

\begin{tabular}{cc}
\hline Label & Definition \\
\hline CB & Control sample: T-beam with no CFRP attached \\
S-Inc & T-beam strengthened with $45^{\circ}$ inclined CFRP attached \\
R-Inc & T-beam preloaded with $45^{\circ}$ inclined CFRP attached \\
S-Str & T-beam strengthened with horizontal straight strips of CFRP attached \\
R-Str & T-beam preloaded with horizontal straight strips of CFRP attached \\
S-Sh & T-beam strengthened with U-wrap CFRP sheets attached \\
R-Sh & T-beam preloaded with U-wrap CFRP sheets attached \\
\hline
\end{tabular}

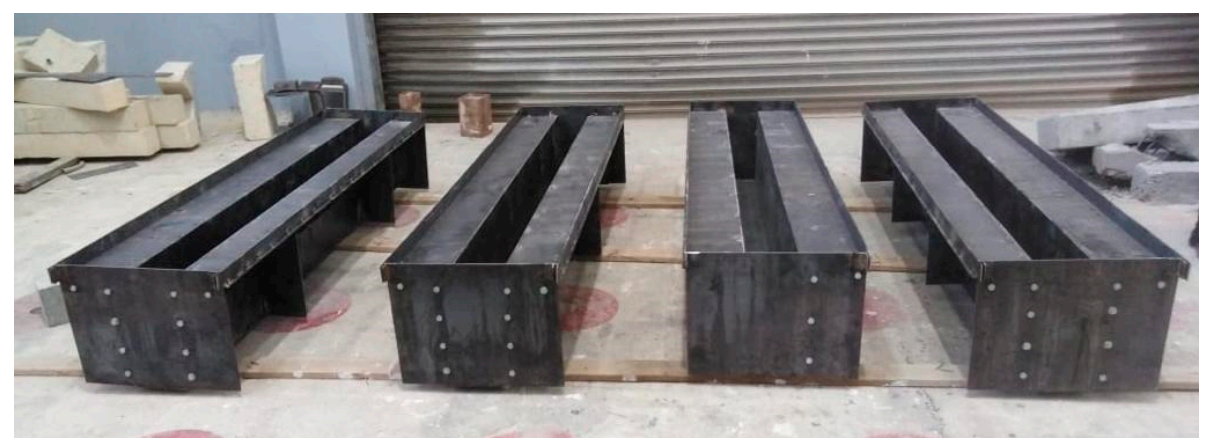

(a) Steel mold formwork

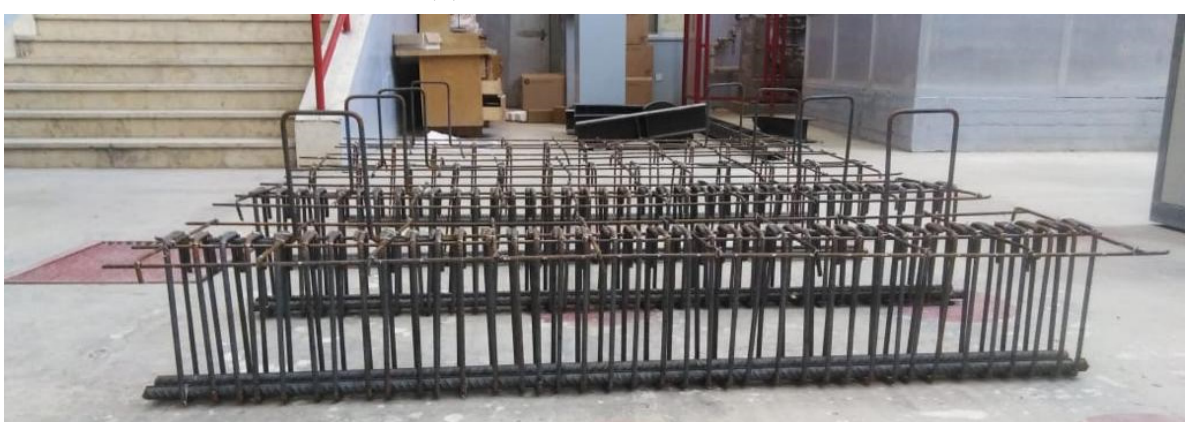

(b) Reinforcement cage

Figure 3. Casting of beams.

\subsection{Test Setup}

A one-point loading test was conducted using a $700 \mathrm{kN}$ capacity MFL Prüf-systeme Universal Testing Machine. All beams were treated as simply supported beams, in which each support was located $100 \mathrm{~mm}$ from each end of the beam. The load was applied in $10 \mathrm{kN}$ increments until failure and was measured using a load cell. At each load increment, the deflection was measured using a dial gauge sensor which was placed at the mid span of the beams. Figure 4 shows the test setup. 

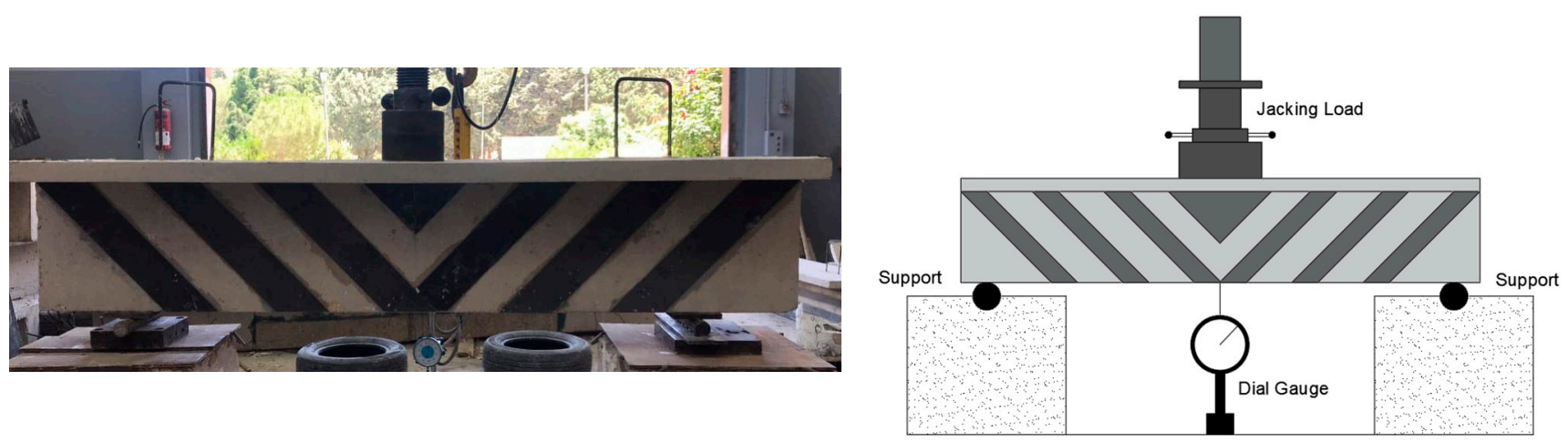

Figure 4. Test setup.

\section{Theoretical Calculations}

The shear strength of all beams was calculated according to ACI 440.2R-17 [37] and ACI 318-19 [38]. The capacity calculations consisted of three parts: the contribution of concrete, reinforcement steel, and the CFRP laminates and sheets. The ACI code defines the theoretical shear strength as

$$
O V_{n}=O\left(V_{c}+V_{s}+\Psi_{f} V_{f}\right)
$$

where $O$ is a strength reduction factor ( 0.75 for shear), $V_{n}$ is the nominal shear strength, $V_{c}$ is the nominal shear strength provided by concrete with steel flexural reinforcement, $V_{s}$ is the nominal shear strength provided by steel stirrups, $\Psi_{f}$ is a strength reduction factor for CFRP ( 0.95 for completely wrapped members or 0.85 for three-side and two-opposite-sides schemes), and $V_{f}$ is the nominal shear strength provided by CFRP.

The terms $V_{c}$ and $V_{s}$ were calculated according to the ACI 318-19 [38], while the contribution of the carbon fiber was calculated according to ACI 440.2R-17 [37] based on the following equations.

$$
\begin{gathered}
V_{f}=\frac{A_{f v} f_{f e}(\sin \alpha+\cos \alpha) d_{f v}}{S_{f}} \\
A_{f v}=2 n t_{f} w_{f}
\end{gathered}
$$

where $A_{f o}$ is the area of FRP shear reinforcement with spacing $s, f_{f e}$ is the effective stress in the FRP, $\alpha$ is the angle of application of the primary FRP reinforcement direction relative to the longitudinal axis of the member, $d_{f v}$ is the effective depth of FRP shear reinforcement, $S_{f}$ is the center-to-center spacing of the FRP strips, $n$ is the number of plies of FRP reinforcement, $t_{f}$ is the nominal thickness of one ply of FRP reinforcement, and $w_{f}$ is the width of FRP reinforcing plies.

\section{Results and Discussion}

\subsection{General Behavior and Failure Modes}

All beams failed in shear. For the control beam, diagonal shear cracks started to appear near the support at a jack load of $135 \mathrm{kN}$. Upon increasing the load, the diagonal cracks became wider and propagated upward with an inclination of about $45^{\circ}$, causing the failure of the beam.

For group 2, hair cracks appeared near the support at a jack load of $200 \mathrm{kN}$; however, one of the diagonal cracks started propagating behind the carbon fiber until it reached the upper face of the beam near the loading point, causing the failure (Figure 5a). It can be seen from Figure $5 b$ that side cover separation had occurred just before the failure at the areas where no carbon fiber was placed near the support. 


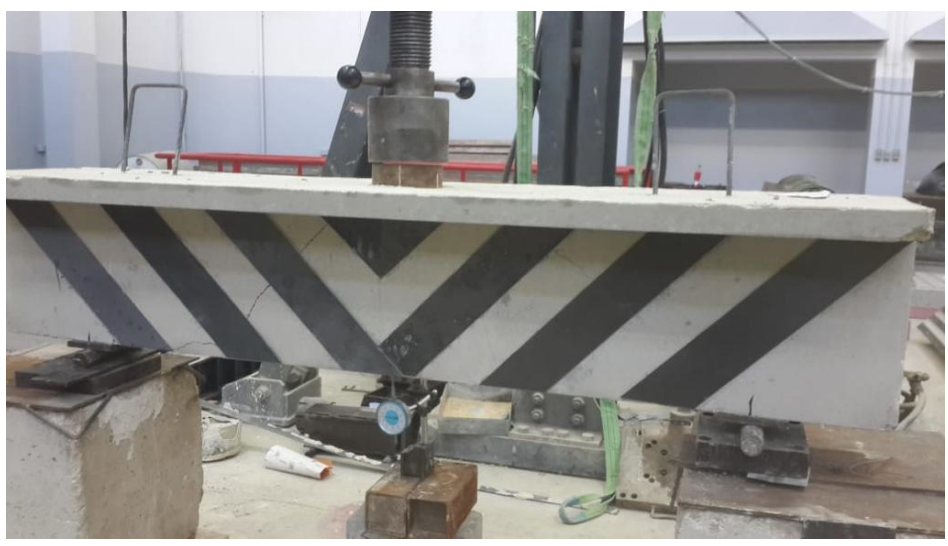

(a) Group 2 shear failure

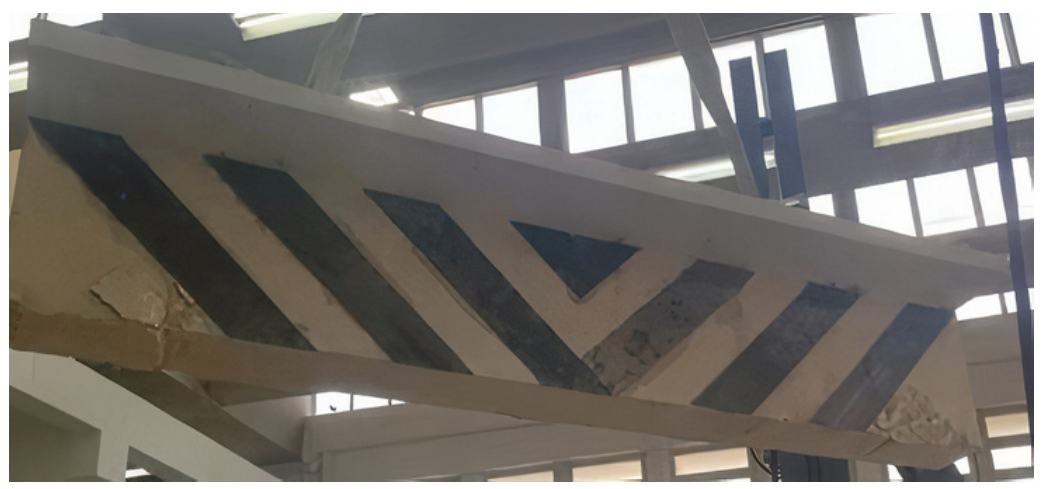

(b) Group 2 side cover separation

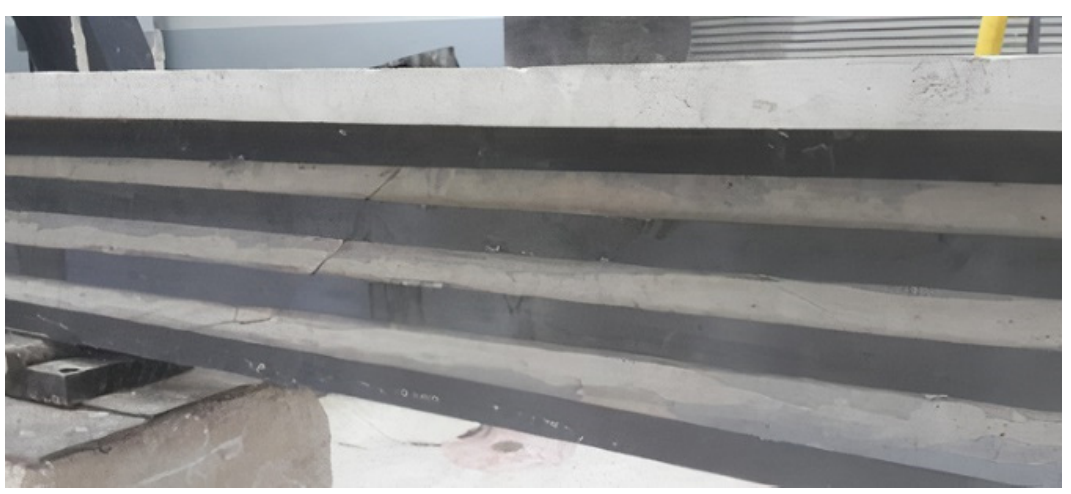

(c) Group 3 shear failure

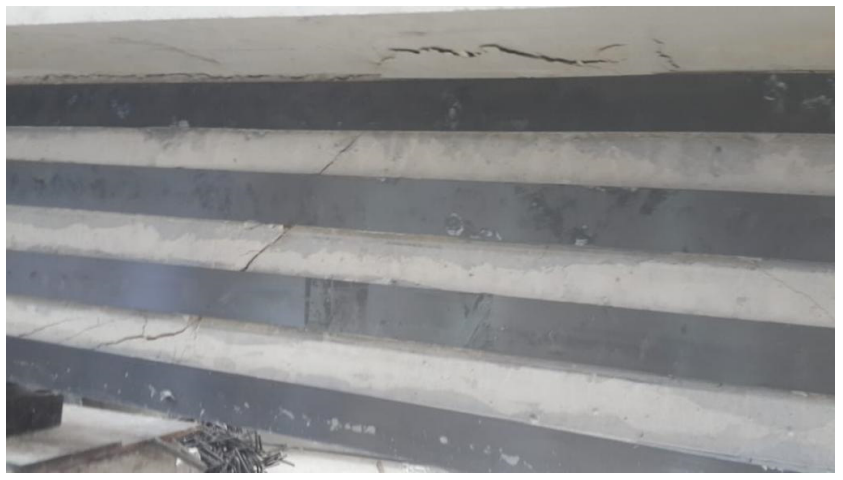

(d) Group 3 diagonal shear crack

Figure 5. Cont. 


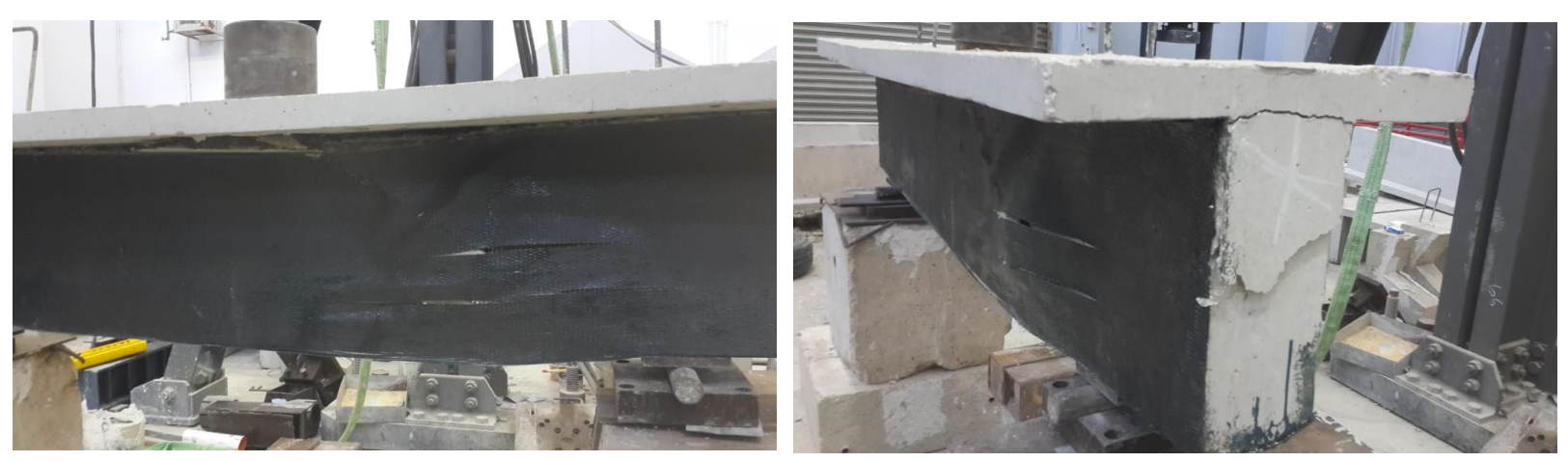

(e) Group 4 failure mode

Figure 5. Failure modes of beams.

For group 3, the same shear cracks were recorded as group 2 at a jack load of $270 \mathrm{kN}$. Partial debonding of the carbon fiber strips near the support area was noticed at failure; however, no debonding was recorded during the test. Further, no side cover separation was noticed. This might be attributed to the configuration of the carbon fiber used, as all the beam side faces were confined longitudinally with horizontal carbon fiber strips, while for group 2, and due to the inclination of the carbon fiber strips, a small area near the support did not have any carbon fiber attached. Figure $5 \mathrm{c}, \mathrm{d}$ illustrates the failure mode of group 3.

Because of the full wrapping of the beams' web in group 4, the shear cracks were hard to notice during the test. At failure, rapture and debonding of the carbon fiber sheet had occurred on the side face of the beam. The carbon fiber had also lost its bond with the concrete at the bottom face with concrete cover separation near the middle third of the span length as shown in Figure 5e.

For beams preloaded with CFRP, new cracks were seen to appear; however, the same cracks that happened in the preloading stage continued their widening and propagation until reaching the upper face of the beam, near the loading point, and caused failure.

\subsection{Experimental Shear Capacity}

The experimental shear capacity results of all the beams are summarized in Table 8. All the beams strengthened and preloaded with CFRP in all configurations showed higher results compared to the CB. This agrees well with the findings of Jayaprakash et al. [36]. The results indicated that for strengthened beams, horizontal straight CRP strips recorded the highest shear capacity among all the samples with an increase of $100 \%$, followed by sheets and $45^{\circ}$ inclined configurations with increases of $41 \%$ and $26 \%$, respectively. This might be attributed to the presence of internal steel stirrups distributed along the beam's length at $50 \mathrm{~mm}$ spacing and their interaction with the CFRP reinforcement, as this finding is also proved by Bae et al. [26].

For the rehabilitation process, the highest increase was recorded for the horizontal straight strips scheme with an increase of $73 \%$, followed by the rehabilitation of beams with sheets and $45^{\circ}$ inclined configurations with increases of $28 \%$ and $21 \%$, respectively. It can be noticed that all the schemes behaved in the same pattern in both the strengthening and rehabilitation of beams, i.e., the horizontal straight strips recorded the highest increase in capacity, followed by sheets and then the $45^{\circ}$ inclined strips. Figure 6 shows a comparison between the experimental results.

It can also be noted that beams strengthened with CFRP recorded higher values than the beams preloaded with the same CFRP scheme. This does not agree with the findings of Jayaprakash et al. [36], where the authors indicated that, as compared to the strengthened beams, the use of CFRP strips for the rehabilitation process recorded better results. 
Table 8. Experimental test results.

\begin{tabular}{cccc}
\hline Sample & Experimental Shear Capacity (kN) & \multicolumn{2}{c}{ Increase (\%) } \\
\hline CB & 160 & $22 \%$ & $0 \%$ \\
\hline S-Inc1 & 195 & $29 \%$ & $26 \%$ \\
S-Inc2 & 207 & $28 \%$ & \\
S-Inc3 & 204 & $25 \%$ & $21 \%$ \\
R-Inc1 & 200 & $21 \%$ & \\
R-Inc2 & 193 & $16 \%$ & $100 \%$ \\
R-Inc3 & 186 & $100 \%$ & \\
S-Str1 & 320 & $98 \%$ & $73 \%$ \\
S-Str2 & 317 & $103 \%$ & \\
S-Str3 & 324 & $74 \%$ & \\
\hline R-Str1 & 279 & $78 \%$ & \\
R-Str2 & 285 & $68 \%$ & \\
R-Str3 & 268 & $41 \%$ & \\
\hline S-Sh1 & 225 & $37 \%$ & \\
S-Sh2 & 219 & $45 \%$ & $28 \%$ \\
S-Sh3 & 232 & $28 \%$ & \\
\hline R-Sh1 & 205 & $24 \%$ & \\
R-Sh2 & 199 & $32 \%$ & \\
R-Sh3 & 211 & &
\end{tabular}

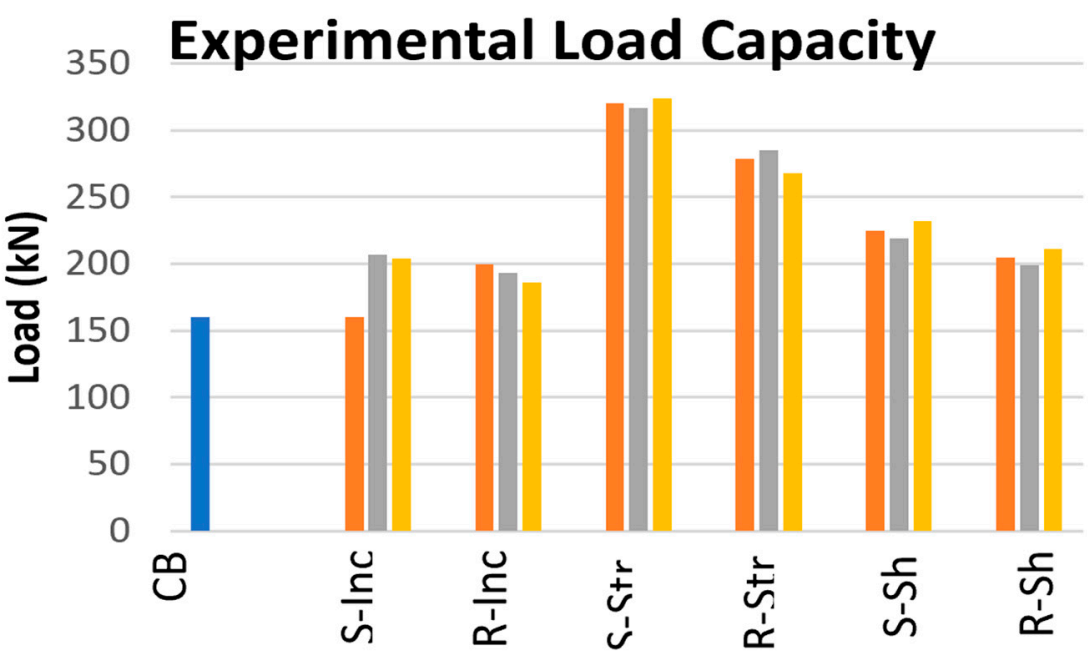

Figure 6. Comparison between the experimental shear capacities for all beams.

\subsection{Experimental Load-Deflection Behavior}

The experimental load-deflection curves for all beams are shown in Figure 7.

All beams showed the same load-deflection behavior during the test. Results clearly indicated that all beams with CFRP attached in any shape or configuration recorded lower deflection values than $C B$, including the preloaded beams at any load value. However, beams with horizontal straight CFRP recorded higher deflection values than the CB at failure. Figure 8 illustrates the deflection of beams along the length for the first sample of each group.

For horizontal straight strips and sheet CFRP configurations, the strengthened beams recorded lower deflections than the preloaded ones, while for the $45^{\circ}$ inclined scheme, the preloaded beam recorded lower deflections up to around $20 \%$ of its capacity and then started to record a higher deflection than the strengthened beam. 


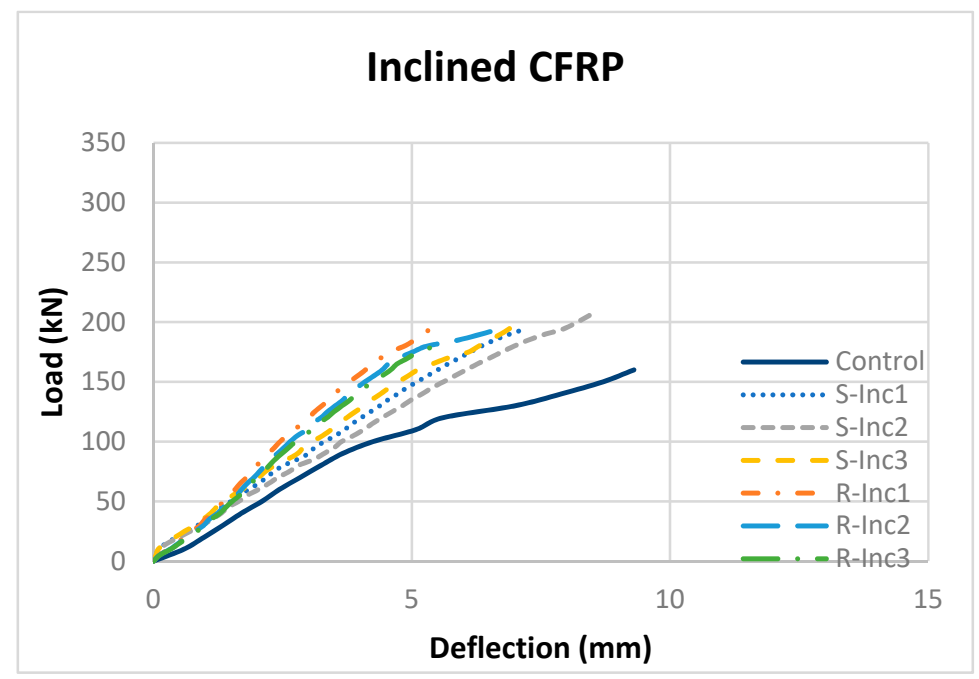

(a)

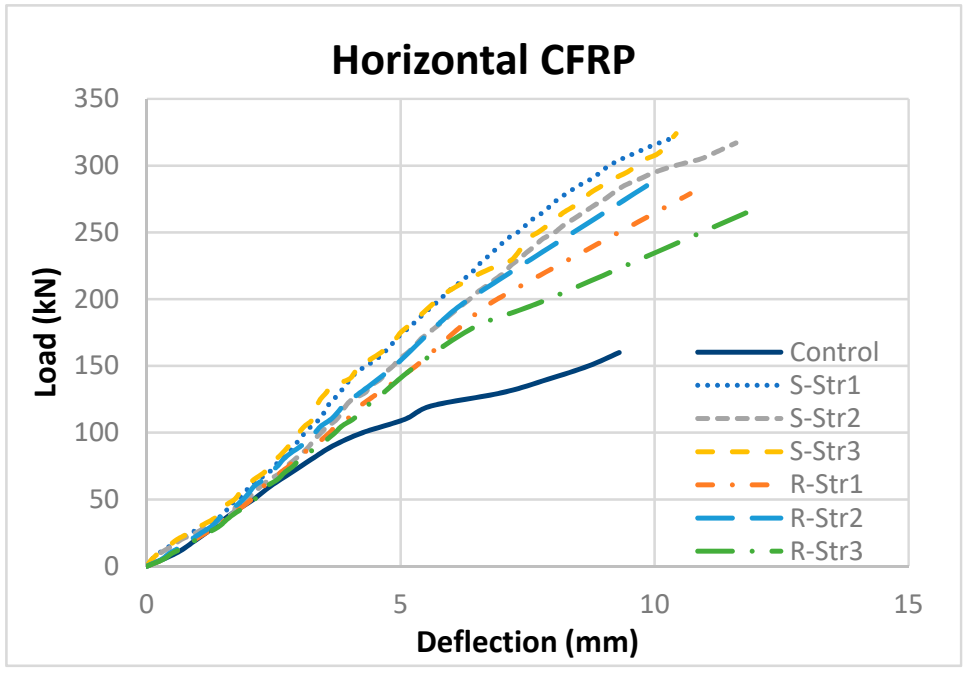

(b)

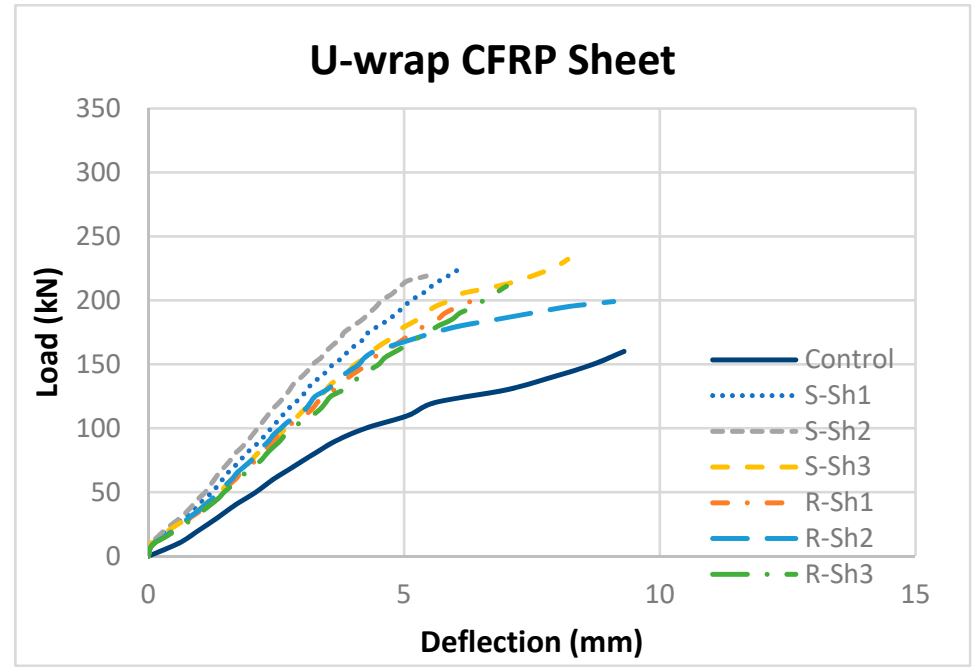

(c)

Figure 7. Experimental load-deflection curves for all beams: (a) inclined-group 2; (b) horizontal straight strips-group 2; (c) U-wrapped sheets-group 3. 


\section{Deflection along the beam's length}

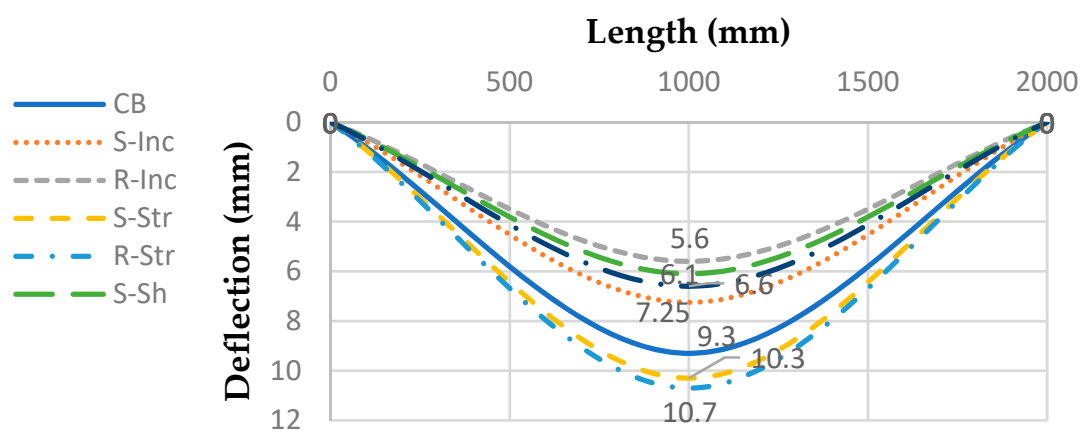

Figure 8. Deflection along the beams' length.

\subsection{Theoretical Results}

The theoretical values were calculated according to ACI 440.2R-17 [37] and ACI 318-19 [38], and the results are illustrated in Table 9.

Table 9. Comparison between experimental and theoretical shear capacity values.

\begin{tabular}{|c|c|c|c|c|}
\hline Sample & $\begin{array}{l}\text { Experimental Shear } \\
\text { Capacity }(\mathbf{k N})\end{array}$ & $\begin{array}{c}\text { Theoretical Shear } \\
\text { Capacity }(\mathbf{k N})\end{array}$ & \multicolumn{2}{|c|}{ Percent Increase (\%) } \\
\hline $\mathrm{CB}$ & 160 & 157.6 & \multicolumn{2}{|c|}{$1 \%$} \\
\hline S-Inc1 & 195 & 231.2 & $-19 \%$ & \\
\hline S-Inc2 & 207 & 231.2 & $-12 \%$ & $-15 \%$ \\
\hline S-Inc3 & 204 & 231.2 & $-13 \%$ & \\
\hline R-Inc1 & 200 & 231.2 & $-16 \%$ & \\
\hline R-Inc2 & 193 & 231.2 & $-20 \%$ & $-20 \%$ \\
\hline R-Inc3 & 186 & 231.2 & $-24 \%$ & \\
\hline S-Str1 & 320 & 308.9 & $3 \%$ & \\
\hline S-Str2 & 317 & 308.9 & $3 \%$ & $4 \%$ \\
\hline S-Str3 & 324 & 308.9 & $5 \%$ & \\
\hline R-Str1 & 279 & 308.9 & $-11 \%$ & \\
\hline R-Str2 & 285 & 308.9 & $-8 \%$ & $-11 \%$ \\
\hline R-Str3 & 268 & 308.9 & $-15 \%$ & \\
\hline S-Sh1 & 225 & 217.5 & $3 \%$ & \\
\hline S-Sh2 & 219 & 217.5 & $1 \%$ & $3 \%$ \\
\hline S-Sh3 & 232 & 217.5 & $6 \%$ & \\
\hline R-Sh1 & 205 & 217.5 & $-6 \%$ & \\
\hline R-Sh2 & 199 & 217.5 & $-9 \%$ & $-6 \%$ \\
\hline R-Sh3 & 211 & 217.5 & $-3 \%$ & \\
\hline
\end{tabular}

It can be seen that the $\mathrm{CB}$ recorded a capacity that was almost the same as its theoretical capacity calculated according to the ACI318-19. However, not all beams with CFRP reached their theoretically predicted capacity. To start with, the code does not differ between the strengthening and rehabilitation of beams; however, the experimental results are not the same. From Table 4, it can be noted that the ACI 440.2R-17 gave conservative results for the strengthening of beams with horizontal straight strips and sheet CFRP configurations. For other specimens, the code overestimated the theoretical capacity by $6-20 \%$.

This might be attributed to the definition of some variables in the code equations, such as the depth of which the CFRP is applied over. The code defines the depth of the CFRP as the distance from which the CFRP starts to the center of the tensile steel. For example, the code treats the beams with horizontal CFRP strips having a ratio of (spacing/width 
of (FRP) equal to one, the same as the sheets. However, in the case of sheets, the whole depth contains CFRP, while for the case of horizontal strips, the spacing between the strips is not considered. This is also confirmed by Tanarslan and Altin [25], as the authors stated that the guidelines failed to account for the $(\mathrm{a} / \mathrm{d})$ ratio and anchorage effects.

Moreover, in the experimental results, the horizontal straight strips provided the highest capacity, followed by the sheets and then the $45^{\circ}$ inclined strips. However, according to the ACI $440.2 \mathrm{R}-17$, the $45^{\circ}$ inclined strips scheme should provide capacities higher than the sheets, which was not the actual case; thus, this is a point to be considered for future calculations.

\section{Conclusions}

From this study, the following can be concluded:

- The results clearly indicate that using externally bonded CFRP laminates and sheets in T-beams is effective in improving the shear capacity.

- For the strengthening and rehabilitation of RC T-beams, the failure to be expected is either pure shear cracks propagated to the tension face of the T-beam, CFRP debonding failure, or CFRP rapture failure associated with cover separation.

- The shear capacity increased for the strengthened T-beams by a range of $26-100 \%$. The highest increase was recorded for the horizontal CFRP strips scheme.

- The shear capacity increased for the preloaded T-beams by a range of $21-73 \%$. The highest increase was recorded for the horizontal CFRP strips scheme.

- The capacities of the strengthened beams were higher than those of their corresponding preloaded T-beams; however, there was no big difference between the experimental results of the strengthening and rehabilitation of T-beams as long as the preloaded Tbeams were not loaded with more than $60 \%$ of their design capacity. After loading the beams up to $60 \%$ of the ultimate load, the dial gauge returned to zero deflection and all beams returned to their initial condition; thus, it is concluded that no significant damage occurred.

- For the experimental load-deflection curves, all T-beams exhibited almost linear trends with different slopes.

- The deflection recorded with the use of CFRP was lower than that of the control T-beam at any load values; however, the deflection at failure was not always lower than that of the control T-beam.

- The ACI 440.2R-17 does not differ between the strengthening and rehabilitation of T-beams. Moreover, not all the parameters are considered logically in the calculations; thus, the theoretical results are not always conservative in predicting the shear capacity and the provisions need to be revised.

- The theoretically predicted values according to the ACI $440.2 \mathrm{R}-17$ and the experimental results did not have the same pattern of ordering the highest capacities.

Funding: This research was funded by the University of Jordan.

Institutional Review Board Statement: Not applicable.

Informed Consent Statement: Informed consent was obtained from all subjects involved in the study.

Data Availability Statement: All data of this research were presented in the article.

Acknowledgments: This work was carried out during the sabbatical leave granted to the author Mu'tasime Abdel-Jaber from the University of Jordan during the academic year 2021-2022.

Conflicts of Interest: The author declares no conflict of interest. 


\section{References}

1. Abdel-Jaber, M.S.; Walker, P.R.; Hutchinson, A.R. Shear strengthening of reinforced concrete beams using different configurations of externally bonded carbon fibre reinforced plates. Mater. Struct. 2003, 36, 291-301. [CrossRef]

2. Rasheed, H.A.; Decker, B.R.; Esmaeily, A.; Peterman, R.J.; Melhem, H.G. The Influence of CFRP Anchorage on Achieving Sectional Flexural Capacity of Strengthened Concrete Beams. Fibers 2015, 3, 539-559. [CrossRef]

3. Al-Khafaji, A.; Salim, H. Flexural Strengthening of RC Continuous T-Beams Using CFRP. Fibers 2020, 8, 41. [CrossRef]

4. Triantafillou, T.C. Shear Strengthening of Reinforced Concrete Beams Using Epoxy-Bonded FRP Composites. ACI Struct. J. 1998, 95, 107-115.

5. Abdel-Jaber, M. Shear Strengthening of Reinforced Concrete Beams Using Externally Bonded Carbon Fibre Reinforced Plates. Ph.D. Thesis, Oxford Brookes University, Oxford, UK, 2001.

6. Teng, J.G.; Smith, S.T.; Yao, J.; Chen, J.F. Intermediate Crack-induced De-bonding in RC Beams and Slabs. Constr. Build. Mater. 2003, 17, 447-462. [CrossRef]

7. Chen, J.-F.; Teng, J. Shear capacity of FRP-strengthened RC beams: FRP debonding. Constr. Build. Mater. 2003, 17, 27-41. [CrossRef]

8. Bousselham, A.; Chaallal, O. Shear Strengthening Reinforced Concrete Beams with Fiber-Reinforced Polymer: Assessment of Influencing Parameters and Required Research. ACI Struct. J. 2004, 101, 219-227.

9. Zhang, Z.; Hsu, C.-T.T. Shear Strengthening of Reinforced Concrete Beams Using Carbon-Fiber-Reinforced Polymer Laminates. J. Compos. Constr. 2005, 9, 158-169. [CrossRef]

10. Adhikary, B.B.; Mutsuyoshi, H. Shear strengthening of reinforced concrete beams using various techniques. Constr. Build. Mater. 2006, 20, 366-373. [CrossRef]

11. Barros, J.A.O.; Dias, S.J.E.; Lima, J.L.T. Efficacy of CFRP-based techniques for the flexural and shear strengthening of concrete beams. Cem. Concr. Compos. 2007, 29, 203-217. [CrossRef]

12. Hafez, A.M.A. Shear Behavior of RC Beams Strengthened Externally with Bonded CFRP-U Strips. J. Eng. Sci. 2007, 35, 361-379.

13. Abdel-Jaber, M.; Shatanawi, A.S.; Abdel-Jaber, M.S. Guidelines for Shear Strengthening of Beams Using Carbon Fiber-Reinforced Polymer (FRP) Plates. Jordan J. Civ. Eng. 2007, 1, 327-335.

14. Bukhari, I.; Vollum, R.; Ahmad, S.; Sagaseta, J. Shear strengthening of reinforced concrete beams with CFRP. Mag. Concr. Res. 2010, 62, 65-77. [CrossRef]

15. Godat, A.; Qu, Z.; Lu, Z.X.; Labossiere, P.; Ye, L.P.; Neale, K.W. Size Effects for Reinforced Concrete Beams Strengthened in Shear with CFRP Strips. J. Compos. Constr. 2010, 14, 260-271. [CrossRef]

16. Al-Tersawy, S.H. Effect of fiber parameters and concrete strength on shear behavior of strengthened RC beams. Constr. Build. Mater. 2013, 44, 15-24. [CrossRef]

17. Alsayed, S.H.; Siddiqui, N.A. Reliability of shear-deficient RC beams strengthened with CFRP-strips. Constr. Build. Mater. 2013, 42, 238-247. [CrossRef]

18. Mostofinejad, D.; Hosseini, S.A.; Razavi, S.B. Influence of different bonding and wrapping techniques on performance of beams strengthened in shear using CFRP reinforcement. Constr. Build. Mater. 2016, 116, 310-320. [CrossRef]

19. Ibrahim, A.M.; Mansor, A.A.; Hameed, M. Structural Behavior of Strengthened RC Beams in Shear using CFRP Strips. Open Civ. Eng. J. 2017, 11, 205-215. [CrossRef]

20. Al-Ghanim, H.; Al-Asi, A.; Abdel-Jaber, M.; Alqam, M. Shear and Flexural Behavior of Reinforced Concrete Deep Beams Strengthened with CFRP Composites. Mod. Appl. Sci. 2017, 10, 110-122. [CrossRef]

21. Abdel-Jaber, M.; Abdel-Jaber, M.; Katkhuda, H.; Shatarat, N.; El-Nimri, R. Influence of Compressive Strength of Concrete on Shear Strengthening of Reinforced Concrete Beams with Near Surface Mounted Carbon Fiber-Reinforced Polymer. Buildings 2021, 11, 563. [CrossRef]

22. Chalioris, C.E.; Kosmidou, P.-M.K.; Papadopoulos, N.A. Investigation of a New Strengthening Technique for RC Deep Beams Using Carbon FRP Ropes as Transverse Reinforcements. Fibers 2018, 6, 52. [CrossRef]

23. Chajes, M.J.; Januszka, T.F.; Mertz, D.R.; Thomson, T.A.; Finch, W.W. Shear strengthening of Reinforced Concrete beams using externally applied composite fabrics. ACI Struct. J. 1995, 92, 295-303.

24. Khalifa, A.; Nanni, A. Improving shear capacity of existing RC T-section beams using CFRP composites. Cem. Concr. Compos. 2000, 22, 165-174. [CrossRef]

25. Tanarslan, H.M.; Altin, S. Behavior of RC T-section beams strengthened with CFRP strips, subjected to cyclic load. Mater. Struct. 2009, 43, 529-542. [CrossRef]

26. Bae, W.; Belarbi, A.; Brancaccio, A. Shear strengthening of full-scale RC T-Beams using externally bonded CFRP sheets. In Proceedings of the First Middle East Conference on Smart Monitoring, Assessment and Rehabilitation of Civil Structures, Dubai, United Arab Emirates, 8-10 February 2011.

27. Kim, Y.; Quinn, K.; Ghannoum, W.; Jirsa, J. Strengthening of Reinforced Concrete T-Beams Using Anchored CFRP Materials. ACI Struct. J. 2012, 111, 1-6. [CrossRef]

28. Soliman, J. General behavior of T-section RC beams strengthened with Epoxy-Bonded carbon strands. MOJ Civil Eng. 2018, 4, 213-217. [CrossRef]

29. El-Saikaly, G.; Godat, A.; Chaall, O. New Anchorage Technique for FRP Shear-Strengthened RC T-Beams Using CFRP Rope. J. Compos. Constr. 2015, 19, 04014064. [CrossRef] 
30. Mhanna, H.H.; Hawilehb, R.A.; Abdallac, J.A. Shear Strengthening of Reinforced Concrete Beams Using CFRP Wraps. Procedia Struct. Integr. 2019, 17, 214-221. [CrossRef]

31. Benzeguir, Z.E.A.; El-Saikaly, G.; Chaallal, O. Size Effect of RC T-Beams Strengthened in Shear with Externally Bonded CFRP L-Shaped Laminates. J. Compos. Constr. 2020, 24, 04020031. [CrossRef]

32. Tanarslan, H.M.; Yalçınkaya, Ç.; Alver, N.; Karademir, C. Shear strengthening of RC beams with externally bonded UHPFRC laminates. Compos. Struct. 2021, 262, 113611. [CrossRef]

33. Kuntal, V.S.; Chellapandian, M.; Prakash, S.S.; Sharma, A. Experimental Study on the Effectiveness of Inorganic Bonding Materials for Near-Surface Mounting Shear Strengthening of Prestressed Concrete Beams. Fibers 2020, 8, 40. [CrossRef]

34. Chalioris, C.E.; Zapris, A.G.; Karayannis, C.G. U-Jacketing Applications of Fiber-Reinforced Polymers in Reinforced Concrete T-Beams against Shear-Tests and Design. Fibers 2020, 8, 13. [CrossRef]

35. Hassan, S.K.H.; Abdel-Jaber, M.S.; Alqam, M. Rehabilitation of Reinforced Concrete Deep Beams Using Carbon Fiber Reinforced Polymers (CFRP). Mod. Appl. Sci. 2018, 12, 179. [CrossRef]

36. Jayaprakash, J.; Samad, A.A.A.; Ashrabov, A.A.; Choong, K.K. Experimental Investigation on Shear Resistance Behaviour of RC Precracked and Non Precracked T-Beams using Discrete CFRP Strips. Int. J. Integr. Eng. 2009, 1, 1-15.

37. ACI Committee 440. ACI 440.2R-17: Guide for the Design and Construction of Externally Bonded FRP Systems for Strengthening Concrete Structures; American Concrete Institute (ACI): Farmington Hills, MI, USA, 2017; pp. 1-8.

38. ACI Committee 318. Building Code Requirements for Structural Concrete (ACI 318-19)—Commentary on Building Code Requirements for Structural Concrete (ACI 318R-19); American Concrete Institute (ACI): Farmington Hills, MI, USA, 2019; p. 261. 